a cardiac catheterization laboratory with the facilities of a cardiac surgical operating room. ${ }^{4}$ This allowed for immediate postoperative imaging to verify the patency and integrity of the anomalous LCX.

\section{References}

1. Veinot JP, Acharya VC, Bedard P. Compression of anomalous circumflex coronary artery by a prosthetic valve ring. Ann Thorac Surg. 1998;66:2093-4.
2. Chaitman BR, Lespérance J, Saltiel J, Bourassa MG. Clinical, angiographic, and hemodynamic findings in patients with anomalous origin of the coronary arteries. Circulation. 1976;53:122-31

3. Flores RM, Byrne JG. Aortic valve replacement with an anomalous left circumflex coronary artery encircling the aortic anulus. J Thorac Cardiovasc Surg. 2001;121: 396-7.

4. Zhao DX, Leacche M, Balaguer JM, Boudoulas KD, Damp JA, Greelish JP, et al Routine intraoperative completion angiography after coronary artery bypass grafting and 1-stop hybrid revascularization results from a fully integrated hybrid catheterization laboratory/operating room. J Am Coll Cardiol. 2009;53:232-41.

\title{
Successful pediatric single-lung transplantation with previous contralateral pneumonectomy, using controlled "donation after cardiac death" lung, for congenital pulmonary vein stenosis
}

\author{
Amit Pawale, MRCS, ${ }^{\mathrm{a}}$ Michael McKean, MD, FRCPCH,${ }^{\mathrm{b}}$ John Dark, FRCS, ${ }^{\mathrm{a}}$ and Asif Hasan, FRCSCTh, ${ }^{\mathrm{a}}$ \\ Newcastle upon Tyne, United Kingdom
}

\section{CLINICAL SUMMARY}

We report the case of a 10-year-old child who had bilateral congenital pulmonary vein stenosis. He presented for the first time to his local hospital at the age of 4 years with life-threatening hemoptysis and was diagnosed with isolated severe left pulmonary vein stenosis and moderate to severe right upper lobe pulmonary vein stenosis. This was treated with left pneumonectomy. Two years after pneumonectomy, he presented with recurrent hemoptysis and reduced exercise tolerance. During the next 4 years, he underwent sutureless repair of his right pulmonary venous stenosis and multiple balloon dilatations (23). He also had multiple stents placed in these veins. Despite this, he became progressively short of breath and was evaluated for right single-lung transplantation. A 6-minute walk test demonstrated desaturation to $67 \%$ on room air after $245 \mathrm{~m}$. Cardiac catheterization revealed suprasystemic pulmonary pressure. His forced expiratory volume in 1 second was $43 \%$ predicted and height was $126 \mathrm{~cm}$. The computed tomography pulmonary angiogram is shown in Figure 1. We performed a right single-lung transplant using a donation after cardiac death (DCD) lung. The donor was a 13-year-old boy who died of irreversible anoxic cerebral damage after traumatic

\footnotetext{
From the Department of Cardiothoracic Surgery and Transplantation, ${ }^{\mathrm{a}}$ Pediatric Respiratory Medicine, ${ }^{\mathrm{b}}$ Freeman Hospital, Newcastle upon Tyne, United Kingdom. Disclosures: None.

Received for publication Dec 31, 2008; revisions received April 25, 2009; accepted for publication June 4, 2009; available ahead of print Aug 26, 2009.

Address for reprints: Amit Pawale, MRCS, Department of Cardiothoracic Surgery, Freeman Hospital, Newcastle upon Tyne NE7 7DN, United Kingdom (E-mail: amitpawale@doctors.org.uk).

J Thorac Cardiovasc Surg 2010;139:e125-6

$0022-5223 / \$ 36.00$

Copyright (C) 2010 by The American Association for Thoracic Surgery

doi:10.1016/j.jtcvs.2009.06.006
}

asphyxiation. Asystole occurred 15 minutes after withdrawal from ventilation. Eleven minutes later, the lungs were inflated; 6 minutes after this, cold flush preservation was started. The warm uninflated time was 11 minutes, and warm inflated time was 6 minutes. The total warm ischemic time was 17 minutes.

The approach was through a re-do median sternotomy. In addition to severe adhesions, the anatomy was distorted because of a hyperinflated right lung. Cardiopulmonary bypass was established via the right atrium and ascending aorta. The heart was stopped to facilitate the removal of multiple stents incorporated in the left atrial wall. Some deeply

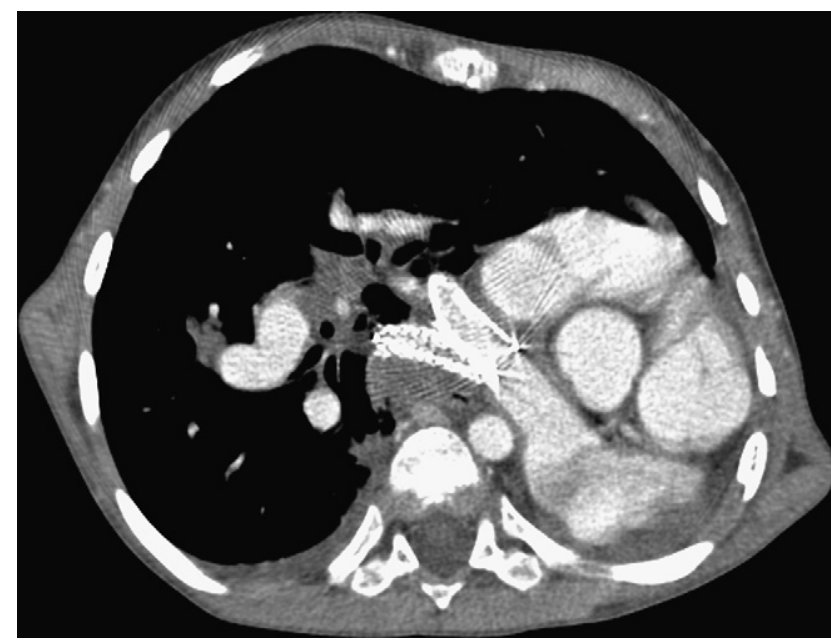

FIGURE 1. Preoperative computed tomography pulmonary angiogram showing previous left pneumonectomy, complete shift of mediastinum to the left and compensatory hyperinflation of the right lung, and patent right upper and lower lobe pulmonary vein stents with stenosis of veins immediately peripheral to them. 

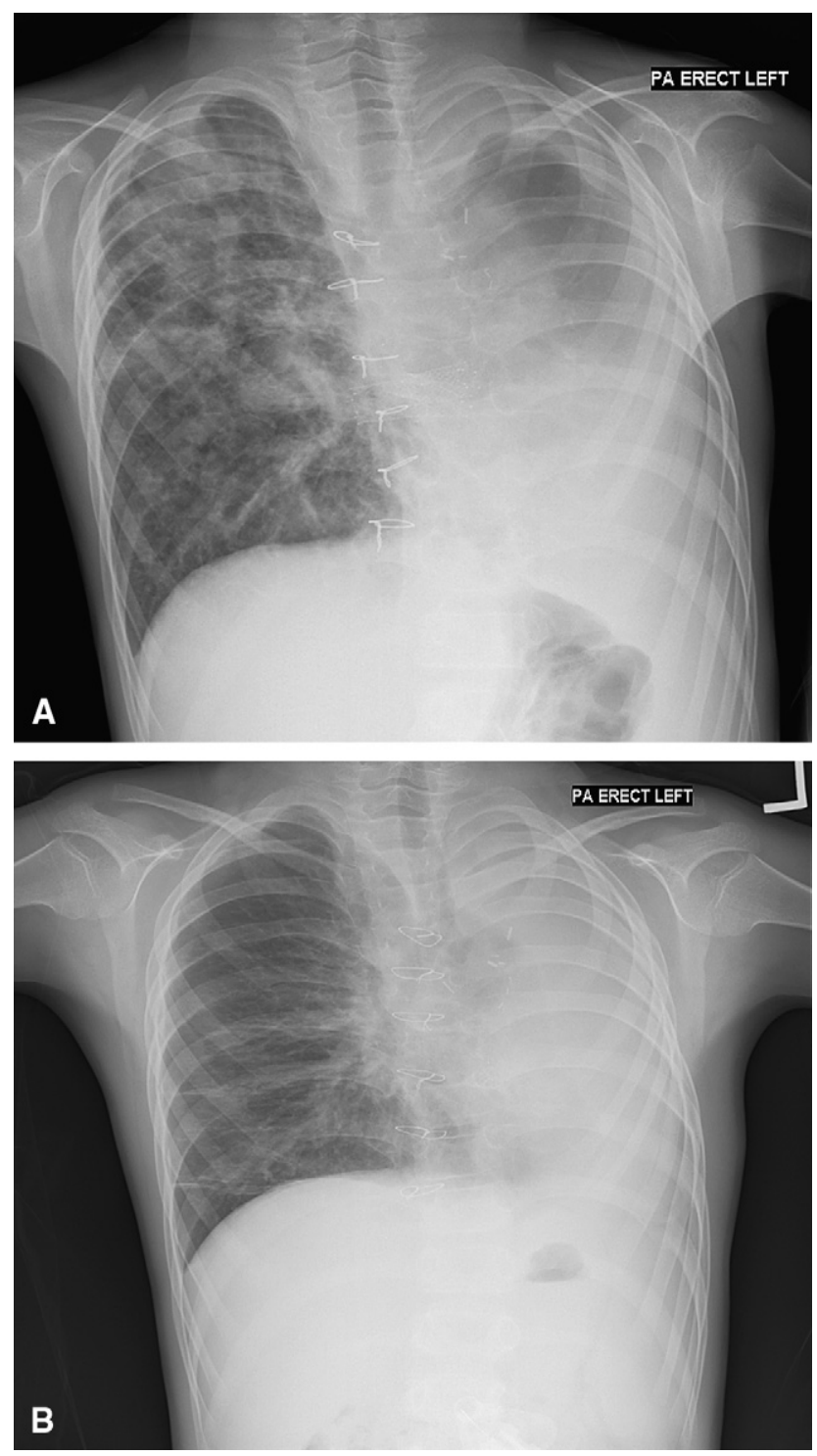

FIGURE 2. A, Pretransplantation chest radiograph showing left pneumonectomy and chronic venous congestion of the right lung. B, Chest radiograph 1 month after right single-lung transplantation using a donation after cardiac death lung. buried stents were left in situ. The ischemic time was 351 minutes (warm ischemic time was 17 minutes, and cold ischemic time was 334 minutes), bypass time was 120 minutes, and crossclamp time was 21 minutes. The patient made an excellent recovery. He was extubated after 6 hours and was transferred to the ward on the first postoperative day. He was ambulatory after 1 week and discharged after 1 month. Fourteen months after the operation, he was well and his last forced expiratory volume in 1 second was $66 \%$ of predicted. His pre- and post-lung transplant chest radiographs are shown in Figure 2.

\section{DISCUSSION}

Single-lung transplantation after previous contralateral pneumonectomy can pose technical difficulties because of mediastinal shift. There is a paucity of literature describing successful single-lung transplantation in this setting. ${ }^{1,2}$ Mortality is high for patients on the waiting list because donor lungs are scarce. The use of DCD lungs can reduce this mortality. 3,4

\section{CONCLUSIONS}

The use of DCD lungs in our center commenced in December 2002. As of early 2009, we have performed 16 transplants using such lungs, with encouraging results. In 2008 , DCD lungs amounted to $15 \%$ of our pulmonary transplant activity. This case demonstrates the feasibility of a successful single-lung transplant in a child with previous contralateral pneumonectomy using a DCD lung.

\section{References}

1. Vergnat M, Farhat F, Tronc F, Jegaden O. Metachronous single lung transplantation after contralateral pneumonectomy. A "big" challenge? Minerva Chir. 2007;62:187-90.

2. Sakiyalak P, Vigneswaran WT. Postpneumonectomy syndrome in single lung transplantation recipient following previous pneumonectomy. Ann Thorac Surg. 2003;75:1023-5.

3. Greco R, Benito J, Gonalez M, De Miguel E, Vazqez J. Lung transplantation from ventilated non-heart-beating donors. Experimental study in a neonatal swine model. J Pediatr Surg. 1999;34:360-6.

4. de Antonio DG, Marcos R, Laporta R, Mora G, García-Gallo C, Gámez P, et al. Results of clinical lung transplant from uncontrolled non-heart-beating donors. J Heart Lung Transplant. 2007;26:529-34. 